\title{
Natural history of snoring and related behaviour problems between the ages of 4 and 7 years
}

\author{
N J Ali, D Pitson, J R Stradling
}

\begin{abstract}
In 1989-90 a survey was carried out of the prevalence of snoring and related symptoms in 7824 to 5 year old children. Two years later, in 1992, the same group of children was studied to gather information on the natural history of snoring and the related behaviour problems.
\end{abstract}

A total of $507 / 782(64 \cdot 8 \%)$ completed questionnaires were received. Comparison of the responses with the 1989-90 survey showed that those who did not reply to the questionnaire were no different from the respondents in terms of the prevalence of snoring, daytime sleepiness, hyperactivity, and restless sleep.

The overall prevalence of habitual snoring did not change between the two surveys $(12 \cdot 1 \%$ in $1989-90 v 11.4 \%$ in 1992$)$, though more than half of the children who snored habitually in the original survey no longer did so. There was little change in the prevalence of hyperactivity $(24 \cdot 2 \%$ in $1989-90 v 20.7 \%$ in 1992) or restless sleep (both 39\%) among the 507 who responded to the present survey. The prevalence of daytime sleepiness, however, did decrease substantially $(20.7 \%$ in $1989-90 v 10.2 \%$ in 1992). There was moderate agreement between the individual questionnaire responses for the $1989-90$ and 1992 surveys for snoring (weighted $\kappa 0.52$ ), but poor agreement for the other symptoms (daytime sleepiness 0.37 , hyperactivity 0.35 , and restless sleep $0 \cdot 38$ ).

Trend analysis showed that the increasing prevalence of sleepiness, hyperactivity, and restless sleep across the snoring categories was highly significant. Daytime sleepiness, hyperactivity, and restless sleep were all significantly more common in the habitual snorers than in those who never snored. Relative risks (95\% confidence interval) were as follows: daytime sleepiness $6.13(2.5$ to 14.9$)$, hyperactivity $2.78(1.6$ to $4 \cdot 7)$, and restless sleep $2 \cdot 3(1.6$ to $3 \cdot 2)$.

Though habitual snoring and the associated behaviour problems resolved spontaneously over two years in about half of the children with these symptoms, there is still the same overall percentage with these problems due to the emergence of new cases.

(Arch Dis Child 1994; 71: 74-76)

Snoring is common in young children ${ }^{12}$ and is often considered to be a trivial symptom. It may, however, indicate the presence of sleep apnoea or a lesser form of sleep disordered breathing. In a large study we reported a high prevalence of habitual snoring in 4-5 year old children living in the community, 1 and found that snoring and sleep disturbance were associated with daytime sleepiness as well as a variety of behavioural problems including inattention, hyperactivity, and aggression. ${ }^{1}$ Snoring with sleep disturbance in young children is most often the result of adenotonsillar hypertrophy ${ }^{3}$ and as these tissues involute in later childhood it would be expected that snoring would become less common. It is not known how long snoring persists in young children, however, nor is it known whether the associated behaviour problems also improve or whether there are longer term effects. This study set out to determine the natural history of snoring and the associated behaviour problems. This was achieved by carrying out a repeat survey in a large group of children who had been studied two years earlier.

\section{Subjects and methods}

SUBJECTS

In our original survey ${ }^{1}$ we identified 996 children born consecutively between 8 January 1985 and 22 September 1985 and living in Oxford from the centralised health visitor register. The parents of $782 / 996(78.5 \%)$ of these children responded to our original questionnaire in 1989-90. These 782 children constituted our study group. At the time of this study they were aged $6 \cdot 5$ to $7 \cdot 5$ years.

\section{METHODS}

The original questionnaire ${ }^{1}$ was slightly modified by asking about the frequency of abdominal pain as well as snoring and behaviour. This new control question had a similar format to the other questions (that is, the

Table 1 Prevalence of snoring and other symptoms for the 507 children who responded to both the 1989-90 and 1992 surveys. Also shown are the results for the 275 children from the 1989-90 study who did not respond to the 1992 survey

\begin{tabular}{|c|c|c|c|}
\hline & $\begin{array}{l}1989-90 \text { Non- } \\
\text { responders } \\
(n=275)\end{array}$ & $\begin{array}{l}\text { 1989-90 } \\
\text { Responders } \\
(n=507)\end{array}$ & $\begin{array}{l}1992 \\
\text { Survey } \\
(n=507)\end{array}$ \\
\hline $\begin{array}{l}\text { Habitual snoring (\%) } \\
\text { Daytime sleepiness (\%) } \\
\text { Hyperactivity (\%) } \\
\text { Restless sleep (\%) } \\
\text { Had tonsillectomy (\%) }\end{array}$ & $\begin{array}{l}13 \\
24 \\
34^{\star} \\
47 \\
1\end{array}$ & $\begin{array}{r}11 \cdot 2 \\
20 \cdot 7 \\
24 \cdot 2 \\
39 \cdot 0 \\
1 \cdot 0\end{array}$ & $\begin{array}{r}11 \cdot 2 \\
10 \cdot 2 \\
20 \cdot 3 \\
39 \cdot 0 \\
4 \cdot 7\end{array}$ \\
\hline
\end{tabular}

«The only difference that approached statistical significance on Wilcoxon rank sum test, $p=0.055$. Otherwise differences were not significant, $p>0 \cdot 25$ for all.

\footnotetext{
Correspondence to: Dr N J Ali, Department of 2A Addory Medicine, Clinic Hills Road, Cambridge CB2 2QQ.

Accepted 28 March 1994

Osler Chest Unit, N J Ali

D Pitson

J R Stradling
} 
Table 2 Relation between responses to the snoring question in the 1992 and 1989-90 surveys. The numbers in each response category are shown for the two surveys. Less than half of those who snored most nights (that is, habitual snorers) in 1989-90 still did so in 1992. Overall there was only moderate agreement between the results of the two surveys (weighted $\kappa 0.52$ )

\begin{tabular}{lccccc}
\hline & \multicolumn{2}{l}{1992 Survey } & & & \\
\cline { 2 - 6 } & Never & Rarely & Sometimes & $\begin{array}{l}\text { Most } \\
\text { nights }\end{array}$ & $\begin{array}{l}\text { Total } \\
\text { number }\end{array}$ \\
\hline Never & 83 & 53 & 23 & 3 & 164 \\
Rarely & 34 & 71 & 41 & 9 & 153 \\
Sometimes & 14 & 40 & 58 & 18 & 130 \\
Most nights & 2 & 6 & 22 & 29 & 60 \\
Total number & 133 & 170 & 144 & 60 & 507 \\
\hline
\end{tabular}

possible responses were, never, rarely, sometimes, and often).

A letter explaining our continuing interest in children's sleep together with the questionnaire were sent to the parents or guardians of the 782 children. No attempt was made to chase non-respondents.

ANALYSIS

All the data for the current survey as well as the previous survey were analysed together using the PC SAS ${ }^{4}$ suite of statistical programs.

Comparison of results of 1989-90 survey for those who did, and those who did not, reply to the 1992 survey

The four possible responses to the questions were given arbitrary scores as follows: never, 1; rarely, 2; sometimes, 3; and most nights, 4 . The two groups (respondents and non-respondents) were then compared using the Wilcoxon rank sum test to establish if there were significant differences between them.

\section{Comparison of individual results for 1989-90 v 1992 surveys}

We compared the individual responses in the present survey with those from the original survey in 1989-90 by calculating values of weighted $\kappa .{ }^{5}$ This mathematically expresses the amount of agreement between the two surveys for the questions about snoring, daytime sleepiness, hyperactivity, and restless sleep.

\section{Examination of the relation between reported} snoring and other symptoms

The 1992 snoring question results were given scores of 1 to 4 , whereas those for the other questions of interest (daytime sleepiness, hyperactivity, restless sleep, and abdominal pain) were collapsed into two categories (never/rarely and sometimes/often), exactly as in our previous survey. ${ }^{1}$ The data were then examined for associations between reported snoring and other symptoms as follows: (a) linear trends across the four snoring categories in the prevalences of daytime sleepiness, hyperactivity, restless sleep, and abdominal pain were tested for statistical significance using $\chi^{2}$ trend analysis; (b) the relative risks and $95 \%$ confidence intervals were calculated for habitual snorers (that is, most nights) $v$ never snorers using the confidence interval analysis computer program. ${ }^{6}$

\section{Results}

We received $507 / 782(64 \cdot 8 \%)$ replies to our questionnaire. There was no significant difference between the 507 who replied to the 1992 survey and the 275 who did not as regards their responses to the 1989-90 questionnaire (table 1), except that there was a slight $(p=0.055)$ excess of children with the symptom of hyperactivity among those who did not respond to the 1992 survey. On the whole the 507 who had responded to the present survey were representative of our study group of 782 children.

The overall prevalence of habitual snoring was no different between the two surveys (table 1), though more than half of the children who snored habitually in 1989-90 no longer did so in 1992 (table 2). Thus this symptom had developed in 31 children since the last survey. In contrast, the prevalence of being sleepy sometimes or often had decreased from $20.7 \%$ in $1989-90$ to just over $10 \%$ in this survey (table 1). The prevalences of restless sleep and hyperactivity did not change between the two surveys. The number of children who had had a tonsillectomy had increased from $1 \%$ to nearly $5 \%$ of children.

There was only moderate agreement between the responses to the snoring question in the two surveys (weighted $\kappa 0.52$, table 2) for example, although habitual snoring had resolved in more than half the children since $1989-90,10 / 60(17 \%)$ who rarely or never snored then now snored on most nights. There was only poor agreement for the questions about sleepiness (weighted $\kappa 0.37$ ), hyperactivity (weighted $\kappa 0.35$ ), and restless sleep (weighted $\kappa 0 \cdot 38$ ).

Trend analysis showed the increasing prevalence of daytime sleepiness, hyperactivity, and restless sleep across the snoring categories to be highly significant. Although the trend in the control question about abdominal pain reached statistical significance, the relation with snoring was much weaker than for the other questions (table 3). Daytime sleepiness, hyperactivity, restless sleep, and abdominal pain were all significantly more common in the

Table 3 Effect of snoring on prevalence of daytime sleepiness, hyperactivity, restless sleep, and abdominal pain ( $n=507)$. Relative risk compares the habitual snorers (most nights) to the never snorers

\begin{tabular}{llllllll}
\hline & $\begin{array}{l}\text { Never } \\
(n=133)\end{array}$ & $\begin{array}{l}\text { Rarely } \\
(n=170)\end{array}$ & $\begin{array}{l}\text { Sometimes } \\
(n=144)\end{array}$ & $\begin{array}{l}\text { Most nights } \\
(n=60)\end{array}$ & $\begin{array}{l}\chi^{2} \text { Trend } \\
(p \text { value })\end{array}$ & $\begin{array}{l}\text { Relative } \\
\text { risk }\end{array}$ & $\begin{array}{l}\text { 95\% Confidence } \\
\text { interval }\end{array}$ \\
\hline Daytime sleepiness (\%) & 5 & 10 & 10 & 28 & $13 \cdot 7(0.0002)$ & $6 \cdot 13$ & $2 \cdot 5$ to $14 \cdot 9$ \\
Hyperactivity (\%) & 15 & 13 & 27 & 40 & $19 \cdot 5(<0 \cdot 0001)$ & $2 \cdot 78$ & $1 \cdot 6$ to $4 \cdot 7$ \\
Restless sleep (\%) & 28 & 32 & 49 & 70 & $27 \cdot 7(<0 \cdot 0001)$ & $2 \cdot 3$ & 1.6 to $3 \cdot 2$ \\
Abdominal pain (\%) & 37 & 43 & 45 & 50 & $6.9(0.01)$ & $1 \cdot 4$ & $1 \cdot 0$ to $2 \cdot 0$ \\
\hline
\end{tabular}


habitual snorers than in those who never snored (table 3).

\section{Discussion}

This is the first study to report the two year natural history of snoring and related symptoms in young children. A large number of young children living in the community was surveyed in 1989-90 and again in 1992. Even though more than half of those who snored habitually in 1989-90 no longer did so, the overall prevalence of snoring has remained essentially unchanged at around $11-12 \%$. Conversely, more than half of the current habitual snorers had developed the symptom since the first survey. Thus the composition of the habitual snorers group had substantially changed and yet we observed the same relations between snoring and daytime behaviour as we had in our original survey of 1989-90.1

The questionnaire used in this study was identical to that used in the original survey, but for the addition of a control question about abdominal pain. In our previous survey the results of sleep monitoring (with video recording and oximetry) in selected groups of snoring and non-snoring children generally confirmed the results of the questionnaire, thus giving it a degree of objective validity. ${ }^{1}$ Abdominal pain is not a symptom clinically associated with sleep and breathing disorders in children and we included a question about it to test for spurious associations between snoring and other symptoms that would be produced if some parents were simply over-reporting all the symptoms on the questionnaire. There was a weak relation between snoring and abdominal pain, indicating that this type of over-reporting of symptoms did occur. The relation was considerably weaker than for the other symptoms we inquired about (daytime sleepiness, hyperactivity, and restless sleep), however, and so this is unlikely to be the explanation for our findings in this or the previous study.

Nearly $65 \%$ of those sent a questionnaire responded. Analysis of the results of the 1989-90 survey showed that the respondents to the 1992 survey were a representative sample of those who responded to the 1989-90 survey. The response rate was comparable with the original survey where we had an initial response of just over $60 \%$, which increased to $78 \%$ after a reminder letter was sent. In the 1989-90 study there was no significant difference between the results of those who had responded to the first letter and those who had responded to the reminder. Therefore it seemed unlikely that our results would be biased by the slightly lower response rate we achieved and so we did not pursue the non-responders.

Corbo et al studied children aged 6 to 13 years and found that the prevalence of snoring decreased with increasing age, but theirs was a cross sectional study rather than following the true natural history. ${ }^{2}$ In this study (albeit a younger age group than they studied), the prevalence did not decrease between the ages of 4.5 to 5.5 years and 6.5 to 7.5 years, though as already discussed habitual snoring had resolved spontaneously in a substantial number of children.

The prevalence of daytime sleepiness had halved since the 1989-90 survey (from just over $20 \%$ to $10 \%$ ) and yet the association of this symptom with snoring has become more marked (relative risk ratio increased from $1 \cdot 18$ in $1989-90^{1}$ to $6 \cdot 13$ in the 1992 survey). This may be just a statistical 'quirk' due to the smaller number of children who were sleepy in this study. Another plausible explanation is that although it is not unusual for a child of 4 to 5 years to fall asleep during the day (because sleep patterns are not yet firmly established), in a 6 to 7 year old it is an unusual occurrence and more likely to be due to problems with nocturnal sleep quality.

In this survey we asked the parents simply whether a child was considered to be hyperactive. Although this questionnaire definition of hyperactivity is subjective, in our 1989-90 survey we had also used the Conners behaviour rating scale $^{7}$ (a more formal and validated measure of hyperactivity ${ }^{8}$ ) in a subgroup of children and confirmed that snoring and hyperactivity were associated. This study found the same relation of snoring and hyperactivity, even though more than half of the habitual snorers, and those considered to be hyperactive, had developed these symptoms since the last survey. This is suggestive evidence of a causal relation. Conversely, it appears that as the snoring resolves then so do the behaviour problems.

In conclusion, habitual snoring remains a common symptom in 6-7 year old children and is associated with daytime sleepiness, restless sleep, and hyperactivity. Although the snoring, restless sleep, and hyperactivity resolved spontaneously in more than half of the children who had these symptoms two years previously, there remains a significant minority who continue to have problems. The natural history of these children's problems needs to be studied to identify long term consequences and identify those who would benefit from treatment.

NJA was a British Lung Foundation research fellow, DP was supported by the Wellcome Trust, and JRS is a Wellcome senior research fellow.

1 Ali NJ, Pitson D, Stradling JR. Snoring, sleep disturbance, and behaviour in 4-5 year olds. Arch Dis Child 1993; 68: $360-6$

2 Corbo GM, Fuciarelli F, Foresi A, De-Benedetto F. Snoring in children: association with respiratory symptoms and passe smokis 300: 226]. BMๆ 1989; 299: 1491-4.

3 Brodsky L, Moore L, Stanievich JF. A comparison of tonsillar size and oropharyngeal dimensions in children with obstructive adenotonsillar hypertrophy. Int $\mathcal{f}$ Pediatr with obstructive adenotonsilar hyp

4 Cody RP, Smith JK Applied statistics and the SAS programming language. 3rd Ed. New York: Elsevier, 1991. gramming language. 3rd Ed. New York: Elsevier, 1991.
Altman DG. Practical statistics for medical research. London: Chapman and Hall, 1991.

6 Gardner MJ, Altman DG. Statistics with confidence. London: BMJ, 1989.

7 Conners CK. A teacher rating scale for use in drug studies with children. Am $\mathcal{F}$ Psychol 1969; 126: 884-8.

8 Rapoport JL, Benoit M. The relation of direct home observations to the clinic evaluation of hyperactive school age boys. F Child Psychol Psychiatry 1975; 16: 141-7. 